\title{
Oil-based gas washing - flexible tar removal for high-efficient production of clean heat and power as well as sustainable fuels and chemicals
}

\author{
R.W.R. Zwart ${ }^{1)}$ \\ A. van der Drift $^{1)}$ \\ A. Bos ${ }^{1)}$ \\ H.J.M. Visser ${ }^{1)}$ \\ M.K. Cieplik ${ }^{1)}$ \\ H.W.J. Könemann ${ }^{2)}$
}

1) Energy research Centre of the Netherlands (ECN) P.O. Box 1, 1755 ZG Petten, the Netherlands (for correspondence)

2) Dahlman Industrial Group, P.O. Box 438, 3144 AK Maassluis, the Netherlands 


\title{
Oil-Based Gas Washing-
} Flexible Tar Removal for High-Efficient Production of Clean Heat and Power as Well as Sustainable Fuels and Chemicals

\author{
R.W.R. Zwart, ${ }^{a}$ A. Van der Drift, ${ }^{a}$ A. Bos, ${ }^{a}$ H.J.M. Visser, ${ }^{a}$ M.K. Cieplik, ${ }^{a}$ and H.W.J. Könemann ${ }^{b}$ \\ ${ }^{a}$ Energy research Centre of the Netherlands (ECN), P.O. Box 1, 1755 ZG Petten, The Netherlands; \\ (for correspondence) \\ ${ }^{\mathrm{b}}$ Dahlman Industrial Group, P.0. Box 438, 3144 AK Maassluis, The Netherlands
}

Published online 12 August 2009 in Wiley InterScience (www.interscience.wiley.com). D0I 10.1002/ep.10383

The Energy research Centre of the Netherlands (ECN) and Dablman Industrial Group have developed a flexible tar removal process. This oil-based gas washing process, OLGA, besides tars, also removes dust as well as contaminants like thiophenes and dioxins from the product gas of a (biomass) gasifier. At ECN, the OLGA technology is currently applied within the Substitute Natural Gas (SNG) production process based on indirect gasification. As OLGA removes tars, but not the valuable lighter bydrocarbons like methane $\left(\mathrm{CH}_{4}\right)$, acetylene $\left(\mathrm{C}_{2} \mathrm{H}_{2}\right)$, and ethylene $\left(\mathrm{C}_{2} \mathrm{H}_{4}\right)$, it plays a crucial role in high-efficient SNG production processes. The OLGA in the past has been demonstrated successfully upstream Fischer-Tropsch diesel (FT) synthesis and in Combined Heat and Power (CHP) line ups as well though, where in the latter case besides the crucial tar removal it showed also to remove dioxins present in the product gas. As such, OLGA plays a

(C) 2009 American Institute of Chemical Engineers crucial role in the production of clean heat and power. (c) 2009 American Institute of Chemical Engineers Environ Prog, 28: 324-335, 2009

Keywords: gasification, gas cleaning, tar removal, dioxins

\section{INTRODUCTION}

Purification of product gas is very important for almost all gasification processes, except for direct combustion after the gasifier. In general, the following gas treatment steps can be identified, summarized in their most logical order [1]:

- Particulate removal

- Organic (tar) impurities

- Removal of inorganic impurities

- Removal of volatile (alkali/heavy) metals

In general, concentration and composition of particulates and tars are mainly determined by the type of gasifier applied, the other impurities like inorganics and metallic compounds are determined by the choice of feedstock. 


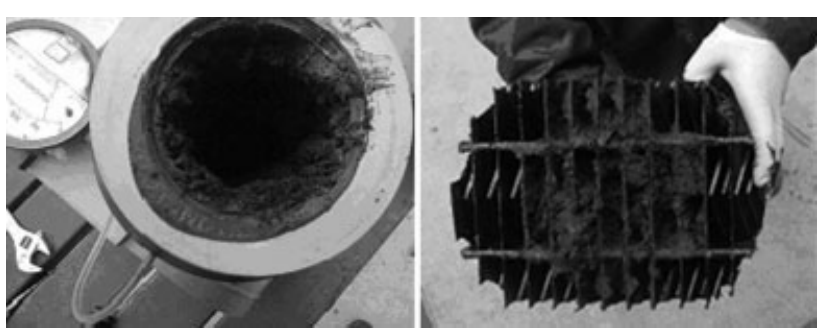

Figure 1. Plugging of piping and fouling of equipment.

\section{The Tar Problem}

The presence of tars in the product gas is seen as the biggest problem in its smooth commercial application as source of sustainable energy. Tar is formed in the gasifier and comprises a wide spectrum of organic compounds, generally consisting of several aromatic rings.

Tar condensation initiates fouling in a biomass gasification process that ultimately can result in the malfunctioning or plugging of equipment, as is shown in Figure 1 [2]. The high maintenance costs and reduction in the yearly operating time due to stand stills leads to an increase in the operating costs. Knowledge about the temperature at which condensation of tar occurs, i.e., the tar dew point, is indispensable for the reliable operation of a biomass gasification process.

\section{Tar Dew Point}

It is important to realize that the tar concentration is not the most important parameter. It is the tar dew point which defines the point at which tars start to become problematic [1]. In general, the lowest temperature in integrated biomass gasification process is determined by downstream equipment and the application of the product gas. As typical tar dew points of the product gas are between 150 and $350^{\circ} \mathrm{C}$, and the lowest temperature in the overall process is typically $30-40^{\circ} \mathrm{C}$, massive tar condensation and tar problems are inevitable if tars are not removed or converted before.

\section{Tar Removal Technologies}

More than 15 years of research by ECN on gasification and product gas cleaning has led to the conviction that tar removal from product gas is best performed by oil scrubbing at a temperature at which water remains in the vapor phase [3]. Tar reduction by measures taken in the gasifier or cracking in downstream reactors can reduce the tar load and simplify tar removal. However, for most applications tar removal remains a necessity. Water can also be used for scrubbing, but mixing dust, tar, and water makes it hard to keep systems running.

\section{THE OIL-BASED GAS WASHING TECHNOLOGY}

The 15 years of experience with tar removal systems at ECN led to the conclusion that mixing of dust, tar, and water should be prevented. That can

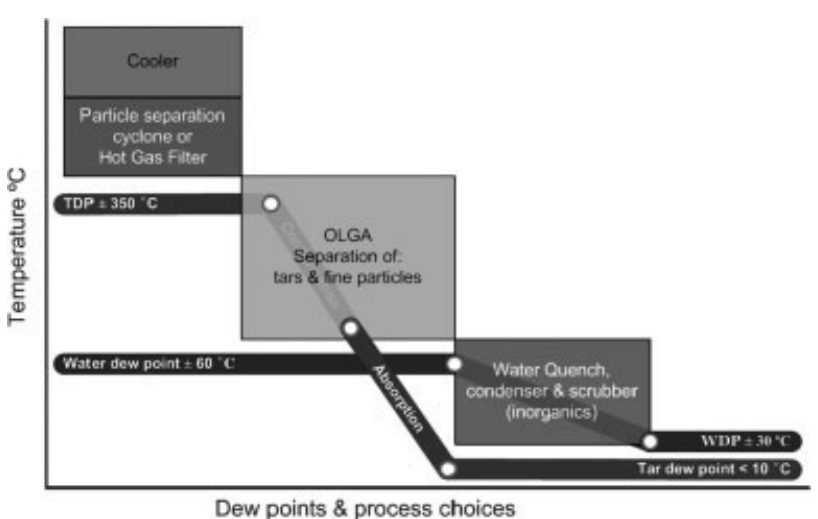

Figure 2. Equipment selection based on dew points.

at least partially be realized with a scrubber operating above the water dew point of the gas using a scrubbing liquid compatible with tar.

If the right scrubbing liquid is chosen, it can absorb tar from producer gas down to a vapor pressure far below that of saturated vapor. Usually, that suffices to prevent tar condensation in downstream equipment. The technology developed by ECN was given the name OLGA, which stands for oil-based gas washing [3]. A patent was applied in 2001 [4].

\section{Process Philosophy}

The philosophy of OLGA is all about dew point control. In Figure 2, the tar and water dew points are shown, together with the logical process steps.

First, the product gas is cooled from typically 700$900^{\circ} \mathrm{C}$ to the OLGA inlet temperature of $450^{\circ} \mathrm{C}$. Upstream OLGA, coarse solids are separated via cyclones. Fine solid aerosols are removed by OLGA.

In OLGA, the tars are separated, first by condensation of heavy tars by cooling the gas from $450^{\circ} \mathrm{C}$ to just above the water dew point and secondly by absorption of light tars. The key philosophy in this is operating OLGA above the water dew point, while decreasing the tar dew point to a level under the lowest process temperature. As such, conventional water-based scrubbing technologies can be applied without mixing water and tars.

\section{Principle}

The tar removal principle of OLGA is based on a multiple stage scrubber, as shown in Figure 3, in which the gas is cleaned by special scrubbing oil. In the first section of OLGA (the collector), the gas is gently cooled down by the scrubbing oil. Heavy tar condenses, is collected, and is separated from the scrubbing oil. The heavy tar condensate together with the fine solids is recycled to the gasifier as a liquid.

In the second stage (the absorber/stripper), lighter gaseous tars are absorbed by the scrubbing oil resulting in a product gas practically free from tars and solids. In the absorber column, the scrubbing oil is saturated by these lighter tars. This saturated oil is regenerated in a stripper. Hot air is used to strip the tars of the scrubbing oil. 


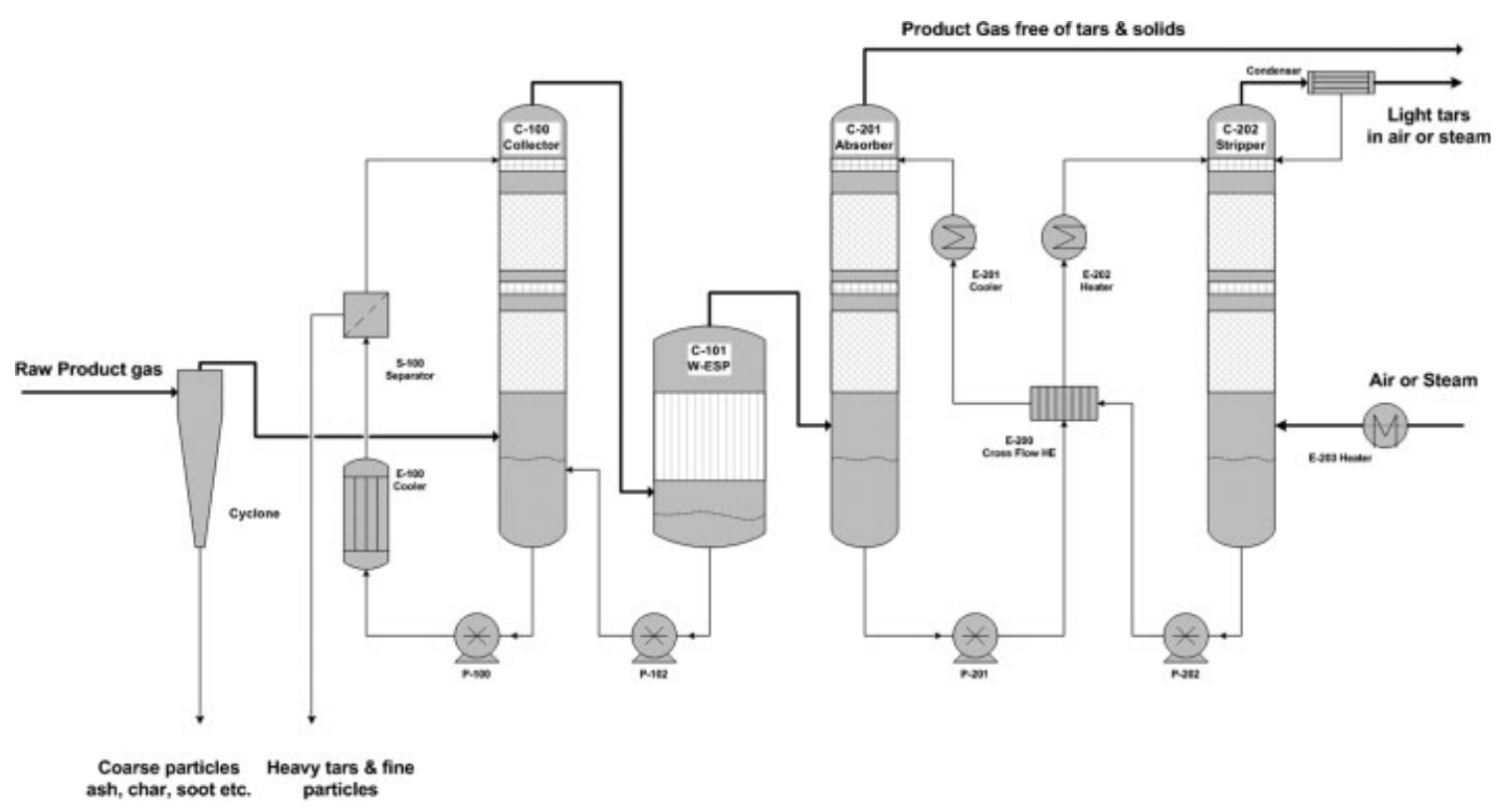

Figure 3. Simplified process flow diagram of OLGA.

This air used for stripping the absorber oil, hence loaded with light tars, is recycled to the gasifier for combusting and as fluidization medium. Hence, the stripper column design is not only based on tar removal, but also on the amount of air that can be used by the gasifier. All heavy and light tars can be recycled to the gasifier where they are destructed and contribute to the energy efficiency. Tar waste streams are efficiently recycled this way.

Between the collector and the absorber, a wet electrostatic precipitator (w-ESP) is installed to remove fine solid aerosols from the product gas. This w-ESP is not necessary when a high efficient solid removal step (i.e. a hot gas filter) is applied upstream OLGA.

\section{Comparison With Alternatives}

An overview of the work performed at ECN on tar prevention, tar cracking and tar removal is given by Rabou et al. [5]. On the subject of tar prevention, the effects of operating conditions, fuel composition and bed materials in fluidized bed gasifiers are covered. Tar cracking results are presented for catalytic materials, high temperature treatment and the use of plasma. Research on tar removal involves the development of both a water-based system and the oil-based OLGA technique.

The R\&D at ECN as well as elsewhere demonstrated that standard technology was insufficient for tar destruction or removal and led to years of research on thermal and catalytic tar cracking. The associated tar reduction, either by measures taken inside the gasifier or tar cracking in downstream reactors, however, is limited [6]. For most applications further tar removal remains a necessity.

For the moment, the (advanced) scrubbing technologies seem to have made the biggest progress, with operating biomass-based CHP plants at e.g.

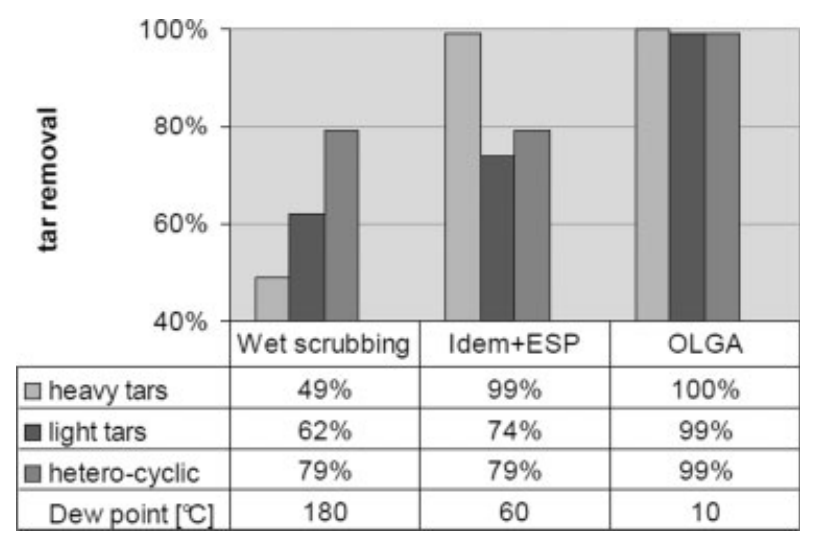

Figure 4. Tar removal efficiency.

Harboøre and Güssing, and water as well as oil(RME scrubbing, OLGA) based technologies being commercially available [6].

ECN operated and tested two aqueous systems as well as the oil-based OLGA system downstream a 500 $\mathrm{kW}_{\text {th }}$ air blown circulating fluidized bed gasifier. The gasifier produces a product gas with a tar load of 10$20 \mathrm{~g} / \mathrm{m}_{\mathrm{n}}{ }^{3}$. Figure 4 compares the tar removal efficiency of the three tested gas cleaning systems.

In the wet scrubbing system (aqueous scrubber) the hetero-cyclic tars were removed for $80 \%$, the light tars for $60 \%$, and the heavy tars for only $50 \%$. The gas was not on specification for a gas engine. With the addition of a wet-ESP the heavy tars were almost completely removed (99\%) and the tar dew point decreased to $60^{\circ} \mathrm{C}$. The product gas could be applied in a gas engine, but the system suffered from wastewater problems.

The OLGA removed the heavy tars totally and the light as well as hetero-cyclic tars for 99\%. The tar 


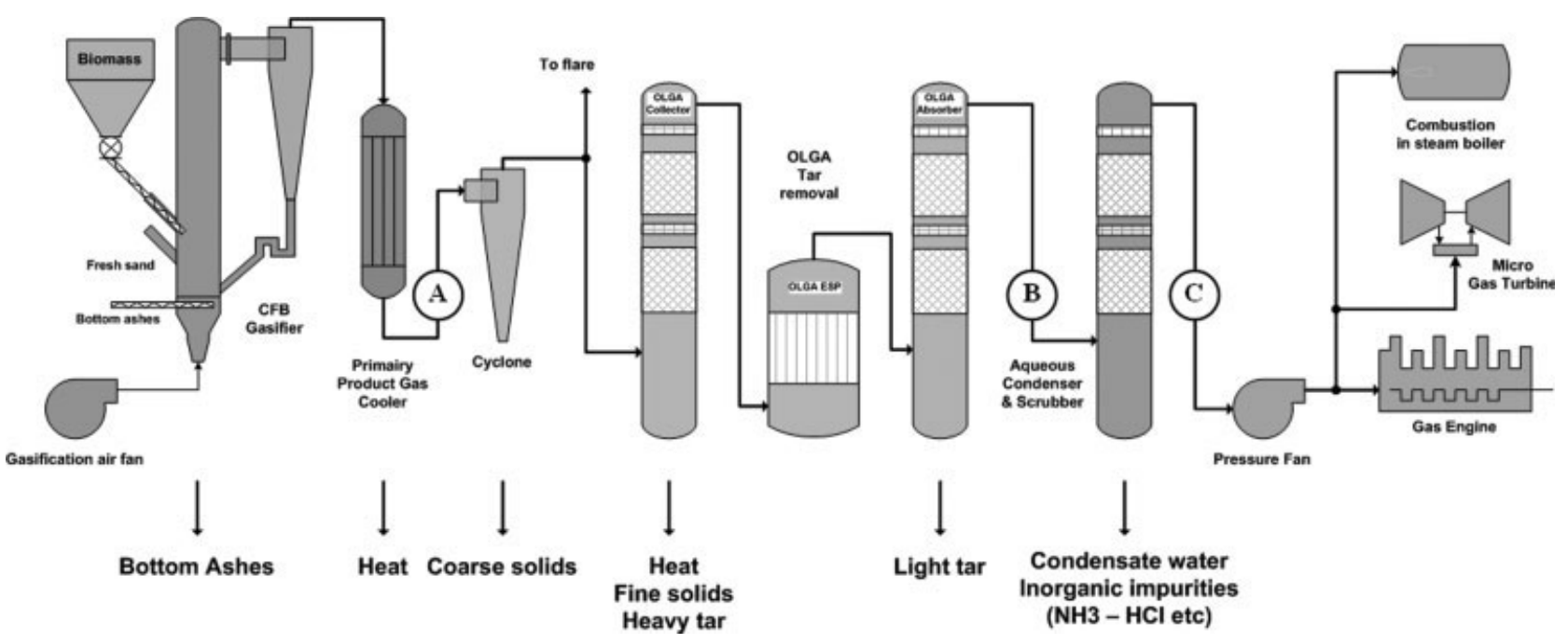

Figure 5. Generic line up of the $500 \mathrm{~kW}_{\text {th }}$ CFB system with OLGA.

dew point was reduced well below a temperature of $10^{\circ} \mathrm{C}$. The water condensate did not contain phenols and the gas could be applied in a gas engine.

Although water in combination with a w-ESP installed could be used for tar scrubbing, the mixing of dust, tar, and water made it hard and expensive to keep systems running. As a result, research by ECN on biomass gasification and producer gas cleaning has led to the conviction that tar removal from producer gas is best performed by oil scrubbing at a temperature at which water remains in the vapor phase.

\section{Ongoing Development}

Although once proclaimed that the tar problem was solved, tar remains an enduring challenge as will be shown in the remaining part of this article. The OLGA process however has been successfully developed and demonstrated for CHP systems based on bubbling (BFB) or circulating fluidised bed (CFB) gasifiers, as described in step 1 later.

In the ongoing development, the focus has shifted from developing and demonstrating the OLGA technology for CHP applications towards improving the OLGA process to make it more versatile, rugged, and economic. It is being adapted to non-CHP applications (step 2) as well as other types of gasifiers and different feedstock's (step 3).

\section{STEP 1: DEMONSTRATION OF HIGH-EFFICIENT PRODUCTION OF CLEAN HEAT AND POWER}

\section{Demonstration of $500 \mathrm{~kW}_{\text {th }}$ CFB-Based CHP System}

The stable production of clean heat and power via biomass gasification and OLGA tar removal was first demonstrated via a duration test of $675 \mathrm{~h}$ with the pilot OLGA installation at ECN [7, 8]. The configuration of this pilot installation is presented in Figure 5. The CFB gasifier was operated on crushed wood pellets. Downstream the gasifier the product gas was cooled down in an air cooler. The gross particles were removed with a cyclone upstream OLGA, whereas OLGA removed the tars and the fine solid aerosols.

The stripper air from OLGA was used as combustion air in the combustor and not as gasifying medium. Ammonia was removed downstream OLGA in two scrubbers. In the first scrubber, water was condensed on cooling, dissolving a part of the $\mathrm{NH}_{3}$. In the second scrubber, the $\mathrm{NH}_{3}$ was further removed with water, without the use of additives. Finally, the product gas passed a booster and fed to a gas engine and combustor.

OLGA could be operated stable with a performance as given in Table 1. The main gas compounds like $\mathrm{CH}_{4}, \mathrm{CO}, \mathrm{H}_{2}, \mathrm{C}_{2} \mathrm{H}_{4}, \mathrm{C}_{2} \mathrm{H}_{6}$, and $\mathrm{N}_{2}$ remained in the product gas, whereas benzene and toluene were removed for 30 and $65 \%$, respectively $[7,8]$.

\section{High Tar Removal Efficiency}

The total tar content was reduced for 99\% from 16.855 to below $200 \mathrm{mg} / \mathrm{m}_{\mathrm{n}}{ }^{3}$. More important, the tar dew point was reduced from over $250^{\circ} \mathrm{C}$ to $5^{\circ} \mathrm{C}$, and the phenol concentration was reduced from approximately $400 \mathrm{mg} / \mathrm{m}_{\mathrm{n}}^{3}$ to below the detection limit. Visual inspection of the gas engine and the oil quality measurements showed similar results as for a gas engine running on natural gas.

\section{Significant Emission Reduction}

Unlike in the industrial combustion processes, formation and emission of dioxins from processes based on the gasification technologies have so far not been studied in detail. Nonetheless, evidence has also been gathered proving that the probable formation mechanisms and the corresponding dioxin levels in the product gas are closely related to tar formation and thus fairly comparable for all gasifiers in which organics (tars) are incompletely converted into product gas [9]. 
Table 1. Typical gas composition at different locations.

\begin{tabular}{|c|c|c|c|c|}
\hline \multirow[b]{3}{*}{ Gas } & & Product gas & After OLGA & Before booster \\
\hline & & \multicolumn{3}{|c|}{ Location (as shown in Figure 5) } \\
\hline & & $\mathbf{A}$ & B & C \\
\hline $\mathrm{H}_{2}$ & vol $\%_{\text {dry }}$ & 7.2 & 7.3 & 7.4 \\
\hline $\mathrm{CO}$ & vol $\%_{\text {dry }}$ & 17.4 & 17.1 & 17.4 \\
\hline $\mathrm{CH}_{4}$ & vol $\%_{\text {dry }}$ & 4.6 & 4.5 & 4.6 \\
\hline $\mathrm{CO}_{2}$ & vol $\%_{\text {dry }}$ & 15.5 & 15.5 & 15.5 \\
\hline $\mathrm{C}_{2} \overrightarrow{\mathrm{H}}_{2}$ & vol $\%_{\text {dry }}$ & 0.2 & 0.2 & 0,2 \\
\hline $\mathrm{C}_{2} \mathrm{H}_{4}$ & vol $\%_{\text {dry }}$ & 2.0 & 1.9 & 1.9 \\
\hline $\mathrm{C}_{2} \mathrm{H}_{6}$ & vol $\%_{\text {dry }}$ & 0.1 & 0.1 & 0.1 \\
\hline $\mathrm{N}_{2}$ & vol $\%_{\text {dry }}$ & 51.3 & 51.6 & 52.0 \\
\hline $\mathrm{H}_{2} \mathrm{O}$ & vol $\%_{\text {dry }}$ & 14.6 & 14.6 & 1.9 \\
\hline Benzene & $\mathrm{ppmV}_{\mathrm{dry}}$ & 3511 & 2415 & 2424 \\
\hline Toluene & $\mathrm{ppmV}_{\mathrm{dry}}$ & 448 & 156 & 158 \\
\hline $\mathrm{NH}_{3}$ & $\mathrm{ppmV}_{\mathrm{dry}}$ & & & \\
\hline $\mathrm{H}_{2} \mathrm{~S}$ & $\mathrm{ppbV}_{\mathrm{dry}}$ & 10 & 10 & 10 \\
\hline Total tar* & $\mathrm{mg} / \mathrm{m}_{\mathrm{n}}^{3}$ dry & 16,855 & 197 & 91 \\
\hline Naphthalene & $\mathrm{mg} / \mathrm{m}_{\mathrm{n}_{2}}^{3}$ dry & 4023 & 38 & 35 \\
\hline Phenol & $\mathrm{mg} / \mathrm{m}_{\mathrm{n}}^{3}$ dry & 386 & $<2.5$ & $<2.5$ \\
\hline Tar aerosols (incl. dust) & $\mathrm{mg} / \mathrm{m}_{\mathrm{n}}{ }^{3}$ dry & - & 10 & $<5$ \\
\hline Tar dewpoint (measured) & ${ }^{\circ} \mathrm{C}$ & $\approx 350$ & - & $-1 \pm 1$ \\
\hline Tar dewpoint (calculated) & ${ }^{\circ} \mathrm{C}$ & $\approx 350$ & 5 & 2 \\
\hline Tar dewpoint (@2.5 bar) & ${ }^{\circ} \mathrm{C}$ & - & 14 & 14 \\
\hline
\end{tabular}

*Accuracy $\pm 200 \mathrm{mg} / \mathrm{m}_{\mathrm{n}}{ }^{3}$.

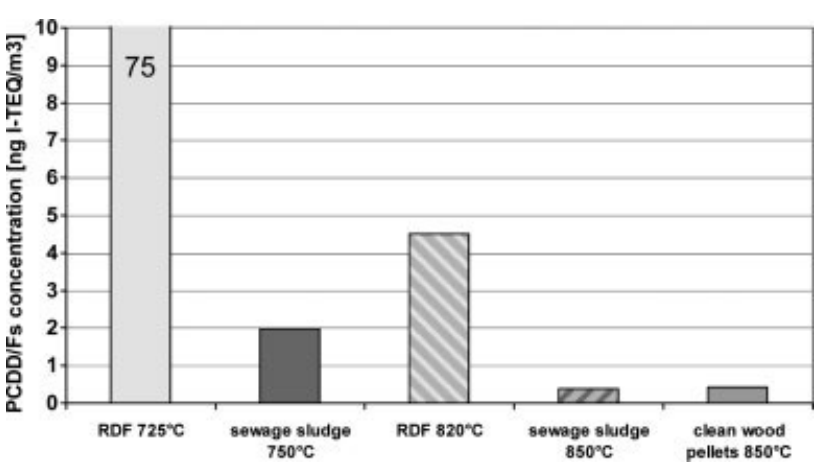

Figure 6. Dioxin levels in product gas in the function of fuel quality and gasification temperature.

At ECN, product gas resulting from the gasification of a variety of fuels in a broad temperature range has been analyzed for dioxin contents. Results of the said measurements [10] are summarized in Figure 6 and show that sizeable amounts of PCDD/Fs are present in the raw producer gas. However, levels of the dioxins vary greatly with the gasification temperature, and in the function of the fuel quality-more specifically its chlorine content. It can be concluded that high levels of chlorine in the fuel promote dioxin formation, particularly at low gasification temperatures $\left(<800^{\circ} \mathrm{C}\right)$. At high conversion temperatures $\left(850^{\circ} \mathrm{C}\right)$, the levels of dioxins decrease sharply, alongside with the corresponding tar levels.

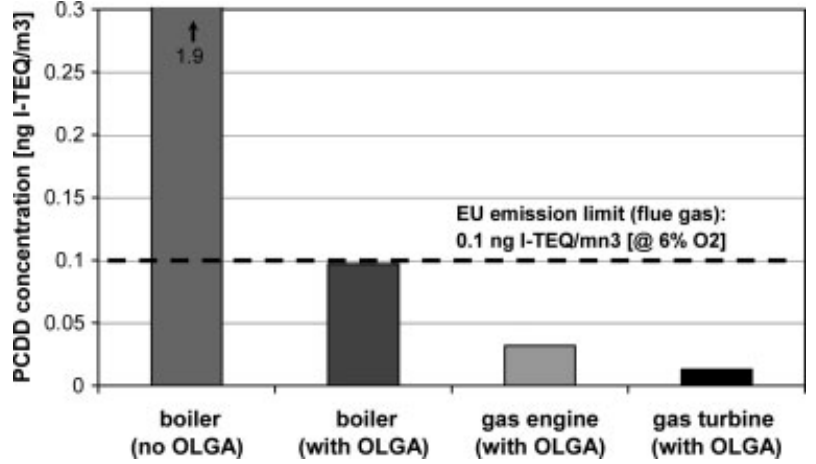

Figure 7. Dioxin emissions from prime movers.

Nonetheless, even in the case of the clean (untreated) wood pellets, the concentration of PCDD/ Fs in the raw producer gas remains in the range of $0.5 \mathrm{ng} \mathrm{I}-\mathrm{TEQ} / \mathrm{m}_{\mathrm{n}}{ }^{3}$.

To enable for the application of the product gas for clean generation of electricity by means of a gas engine or turbine, dioxins emissions have to be taken into account. During the demonstration of the 500 $\mathrm{kW}_{\text {th }}$ system, a threefold of prime movers have been characterized in terms of dioxin emission, namely a water boiler, a gas engine and a micro gas turbine. Data from the said measurements are presented in Figure 7, using clean wood pellets as the reference fuel. 
Table 2. Performance of OLGA in Moissannes.

\begin{tabular}{lcc}
\hline \multicolumn{1}{c}{ Fuel } & Wood sawdust & Grape residues \\
\hline Operation & \multicolumn{2}{c}{ Stable and reliable } \\
Capacity & $<1.1 \mathrm{MW}_{\mathrm{e}}^{*}$ & Full $1.1 \mathrm{MW}_{\mathrm{e}}$ \\
Heavy tars & \multicolumn{2}{c}{ Removed efficiently } \\
Phenol & \multicolumn{2}{c}{ Removed completely** } \\
Naphthalene & $>99 \%$ & According expectations \\
\hline
\end{tabular}

*Because of the low fuel density, the full capacity was not reached.

**Taking into account a detection limit of $<2.5 \mathrm{mg} /$ $\mathrm{m}_{\mathrm{n}}^{3}$.

†During the full load testing on grape residues, the stripper air fan could not reach it's design flow due to a high back pressure at the inlet of gasifier. As such, less tar was stripped from the oil. Using the OLGA simulation model, the expected efficiency at the lower stripper air flow capacity was determined reproducing the same efficiency figures.

The native dioxin contents of the used product gas $0.5 \mathrm{ng}$ I-TEQ $/ \mathrm{m}_{\mathrm{n}}{ }^{3}$ where no OLGA was applied, while it was a factor 10 lower when the gas was purified using the OLGA scrubber. All data on flue gas presented in Figure 7 are normalized to the oxygen concentration of $6 \mathrm{vol} \%$. As a reference, the emission limit of $0.1 \mathrm{ng}$ I-TEQ $/ \mathrm{m}_{\mathrm{n}}{ }^{3}$ as imposed by the European Waste Incineration Directive (EU-WID) for CHP installations is indicated in the figure. As can be seen, dioxin emissions from the water boiler without the application of the OLGA installation are in excess of the EU-WID limit. When cleaning the gas with OLGA, emissions from all three studies prime movers are low, complying with the stringent emission limit.

It can be concluded that the vast majority of dioxins present in the raw producer gas can be captured alongside with tars by means of the OLGA technology [9]. However, as dioxins are captured alongside with tars, this means that the effluent produced by OLGA (i.e. the removed tars), is potentially enriched in dioxins and should be handled with the appropriate care. This will mean that the captured dioxins and tars that are in general recycled as fuel to the gasifier will have to be converted by smartly designing the gasification process.

\section{Demonstration of $4 \mathrm{MW}_{\text {th }}$ Fixed Bed-Based CHP System}

In 2005, the French company Energie Biomasse Viticole (EBV) decided to build a $4 \mathrm{MW}_{\text {th }}$ demonstration plant in Moissannes, France, as a demonstration for several larger commercial plants. The OLGA technology was selected as the preferred tar removal technology after a special fixed bed updraft gasifier by PRMe. Solids were removed by a cyclone and the OLGA w-ESP. The cleaned gas was combusted in Caterpillar engines provided by Eneria to produce $1 \mathrm{MW}_{\mathrm{e}}$ electricity.

The Moissannes demonstration plant was used for two main test runs (fully measured) in 2006. During

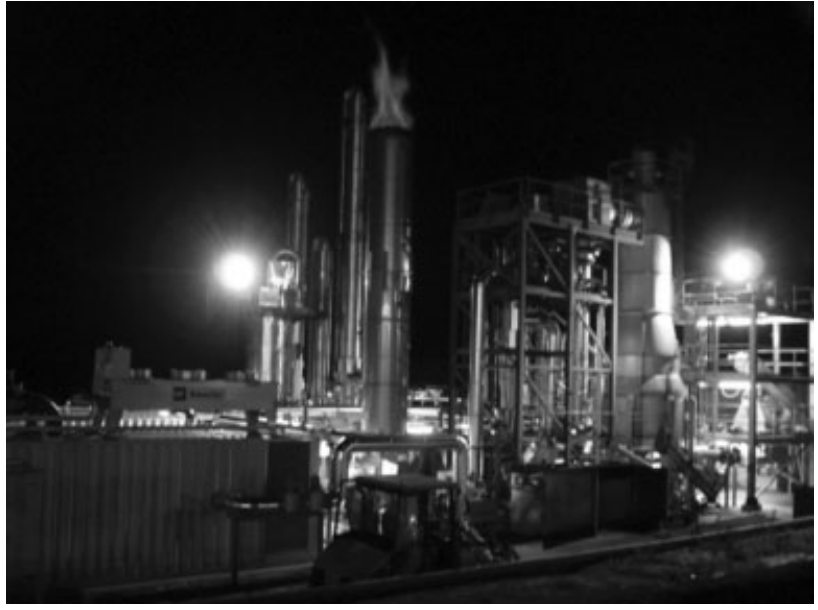

Figure 8. Blue flame during OLGA operation.

both main testing periods, gas analysis were executed to verify the performance of OLGA performance. For these tests, the gasifier was operated on wood sawdust as well as grape residues.

In the raw producer gas, tar concentrations were measured up to $11,000 \mathrm{mg} / \mathrm{m}_{\mathrm{n}}{ }^{3}$, while the tar dew point at the inlet of OLGA exceeded $190^{\circ} \mathrm{C}$. For both fuels tested, the OLGA process worked according to specifications (as shown in Table 2 [11]). The collector and ESP, separating heavy tar from the producer gas, were operating according to design. The absorber/stripper used for separating the light tars also showed good performance, with the key compounds phenol and naphthalene after OLGA sufficiently being removed (below detection limit respectively 99\% removal). During the wine residue tests, the plants power output of $1.1 \mathrm{MW}_{\mathrm{e}}$ was measured by an independent organization.

The performance of OLGA is also shown in Figure 8. This photo was made just before engine start-up, hence at a time where the product gas cleaned by OLGA was still led to the plants flare. The beautiful clear blue flame demonstrates clean gas, free of tars and solids.

\section{STEP 2: DEVELOPING HIGH-EFFICIENT PRODUCTION OF SUSTAINABLE} FUELS AND CHEMICALS

Although originally developed for allowing product gas to be used in gas engines and turbines, the OLGA technology was tested from the beginning also for tar removal upstream catalytic synthesis units, to allow the application of the product gas for the production of sustainable second generation transportation fuels like Fischer-Tropsch (FT) diesel and Substitute Natural Gas (SNG) or even biochemicals already present in the product gas.

\section{Fischer-Tropsch (FT) Diesel Production}

In March 2003, FT products were synthesized from a biomass-derived product gas in a 500-h test [12] with a system based on BFB gasification and OLGA tar removal. Beech was gasified at $850^{\circ} \mathrm{C}$ with 
oxygen as gasifying medium to produce an essentially nitrogen-free product gas and with added steam or $\mathrm{CO}_{2}$ to moderate the temperature in the bed of the gasifier.

The raw product gas passed a high-temperature gas filter to remove essentially all the solids. The tars and BTX were removed in the OLGA unit. The gas leaving OLGA was further cooled and cleaned from e.g., $\mathrm{NH}_{3}, \mathrm{HCl}$, and other inorganic impurities in a water scrubber. Water was condensed from the clean gas and subsequently the gas is compressed to the desired operating pressure of the FT synthesis unit. The basic line up of this system is presented in Figure 9, with the typical gas compositions presented in Table 3 [12].

During the integrated test, the catalyst showed no loss of activity or selectivity, and the composition and quality of the wax and light products produced from beech were identical to products from fossil origin, as

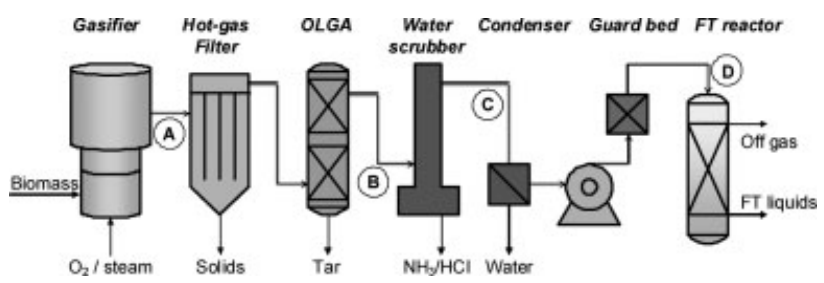

Figure 9. OLGA based biomass to FT-diesel system. was confirmed by off-line analyses in Shell laboratories. Furthermore, the biomass origin was confirmed by carbon 14 dating of the product samples.

Although successful, OLGA based biomass to FTdiesel research was not continued at ECN, as the product gas is preferred for the production of substitute natural gas (SNG) due to the amount of methane and other valuable hydrocarbons already present in the product gas.

\section{Substitute Natural Gas (SNG) Production}

The SNG production process developed by ECN is based on the indirect MILENA gasification technology. The indirect gasifier enables the production of high amounts of methane in the gasifier itself, without requiring oxygen as gasification medium. A key part of the downstream gas cleaning is again the OLGA tar removal system. In further gas cleaning steps unwanted components such as sulfur, chlorine, and carbon dioxide $\left(\mathrm{CO}_{2}\right)$ are removed. The basic line up of this system is presented in Figure 10, with the typical gas compositions presented in Table 4 [13].

With OLGA removing tars without influencing the main composition $\left(\mathrm{CO}, \mathrm{H}_{2}, \mathrm{CO}_{2}\right.$, and $\left.\mathrm{CH}_{4}\right)$ of the product gas it plays a crucial part in a high-efficient SNG production process. In addition, OLGA does not remove water (required in the methanation step) or $\mathrm{C}_{2}$-components like ethylene and acetylene.

Table 3. Typical gas composition at different locations.

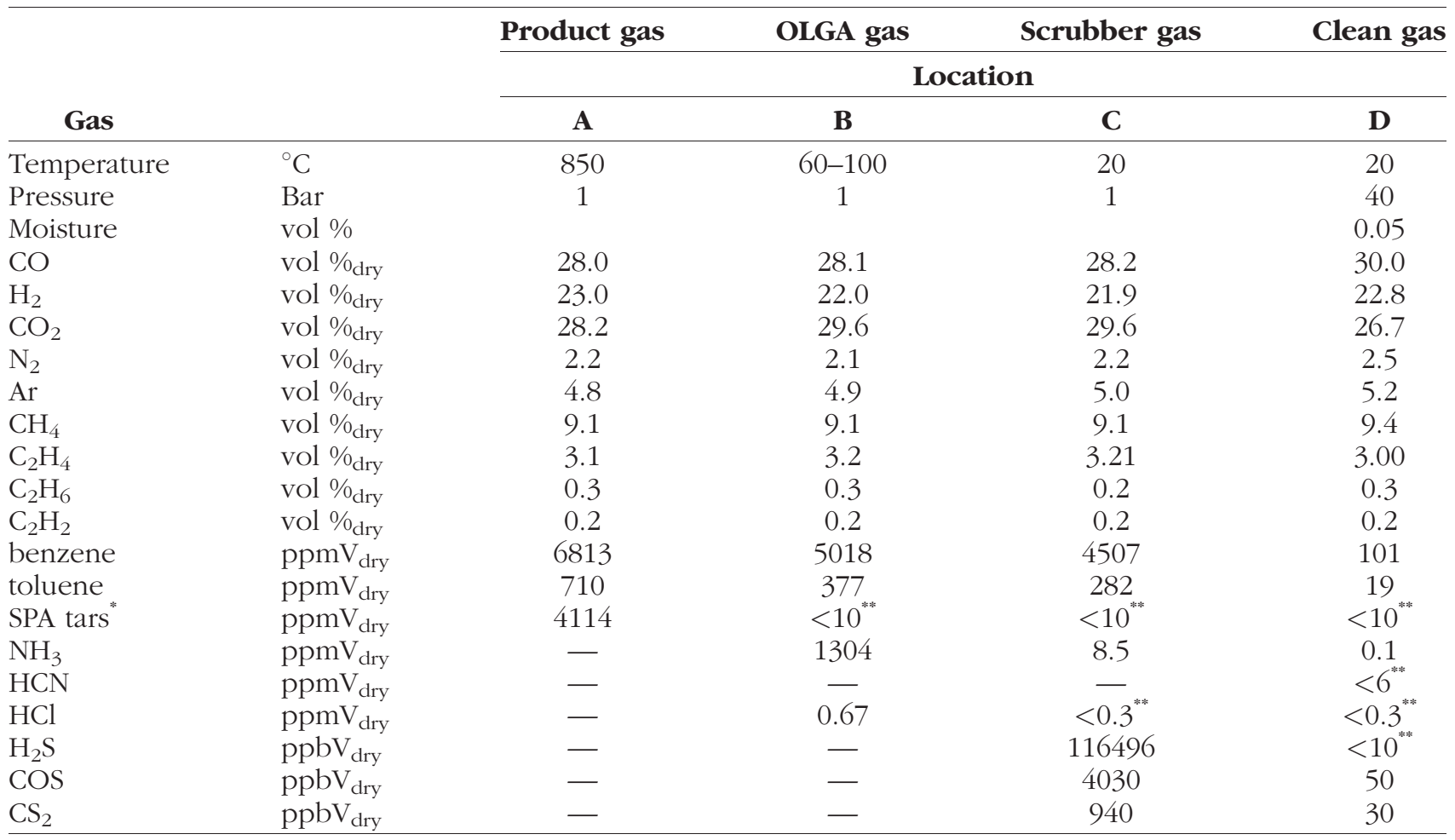

*Concentration of tars measured by solid phase adsorption (SPA).

**Actual concentrations were below detection limit. The reported values are estimated maximum values. 


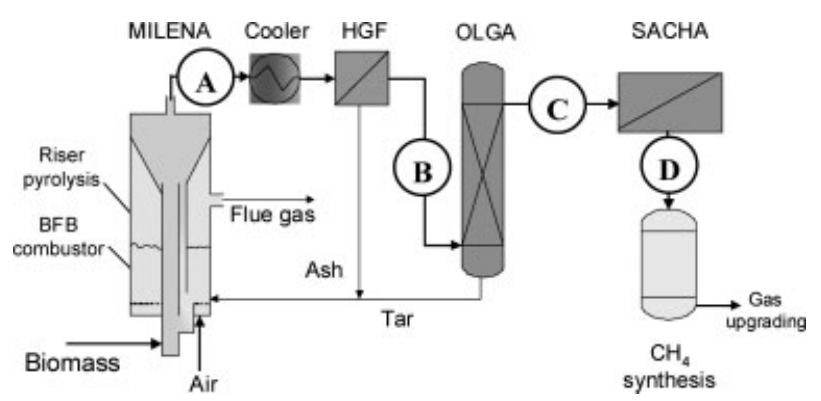

Figure 10. OLGA based biomass to SNG system.

Table 4. Typical gas composition at different locations.

\begin{tabular}{|c|c|c|c|c|c|}
\hline & MILENA & HGF & OLGA & SACHA \\
\hline & & \multicolumn{4}{|c|}{ Location } \\
\hline \multicolumn{2}{|l|}{ Gas } & A & B & C & D \\
\hline $\mathrm{H}_{2}$ & vol $\%_{\text {dry }}$ & 26 & 24 & 24 & 25 \\
\hline $\mathrm{CO}$ & vol $\%_{\mathrm{dry}}$ & 29 & 30 & 31 & 31 \\
\hline $\mathrm{CH}_{4}$ & vol $\%_{\mathrm{dry}}$ & 11 & 12 & 12 & 11 \\
\hline $\mathrm{CO}_{2}$ & vol $\%_{\mathrm{dry}}$ & 22 & 21 & 21 & 21 \\
\hline Sum $\mathrm{C}_{2} \mathrm{H}_{\mathrm{v}}$ & vol $\%_{\mathrm{drv}}$ & 5 & 5 & 5 & 5 \\
\hline $\mathrm{N}_{2}$ & vol $\%_{\text {dry }}$ & 6 & 6 & 6 & 6 \\
\hline $\mathrm{H}_{2} \mathrm{O}$ & vol $\%_{\text {wet }}$ & 40 & 40 & 40 & 40 \\
\hline Total tar & $\mathrm{g} / \mathrm{m}_{\mathrm{n}}{ }^{3}$ & 30 & 30 & 0.6 & - \\
\hline $\begin{array}{c}\text { Tar dew } \\
\text { point }\end{array}$ & ${ }^{\circ} \mathrm{C}$ & $>250^{*}$ & $>250^{*}$ & $76^{* *}$ & - \\
\hline Benzene & $\mathrm{ppmV}_{\mathrm{dry}}$ & 10,193 & 11,141 & 7448 & 6575 \\
\hline Toluene & $\mathrm{ppmV}_{\mathrm{dry}}$ & 1150 & 1423 & 533 & 382 \\
\hline $\mathrm{H}_{2} \mathrm{~S}$ & ppmV $V_{\text {dry }}$ & 96 & 111 & 104 & 0.0 \\
\hline COS & $\mathrm{ppmV}_{\mathrm{dry}}$ & 2.3 & 1.9 & 1.8 & 0.0 \\
\hline $\begin{array}{l}\text { Organic } \\
\text { sulphur }\end{array}$ & $\mathrm{ppmV}_{\mathrm{dry}}$ & - & - & 9 & 6 \\
\hline $\mathrm{HCl}$ & $\mathrm{ppmV}_{\mathrm{dry}}$ & - & - & 0.6 & 0.6 \\
\hline $\mathrm{NH}_{3}$ & $\mathrm{ppmV}_{\mathrm{dry}}$ & 1481 & - & 1539 & 1761 \\
\hline $\mathrm{HCN}$ & $\mathrm{ppmV}_{\mathrm{dry}}$ & 72 & - & 85 & $\sim$ \\
\hline
\end{tabular}

*Actual tar dew point is probably between 350 and $400^{\circ} \mathrm{C}$

**Tar dew point is relatively high due to the limited column lengths of the lab scale OLGA.

The latter ones will (after hydrogenation towards for SNG acceptable $\mathrm{CH}_{4}$ or $\mathrm{C}_{2} \mathrm{H}_{6}$ ) contribute significantly to the heating value and Wobbe index of the SNG. As such, an OLGA-based SNG production process can reach an efficiency for the conversion of biomass to SNG of approximately $70 \%$

Concepts based on "conventional" gas cleaning (e.g., with methanol based Rectisol ${ }^{\circledR}$ washing) or (thermal) tar cracking, by removing these valuable components from the product gas, will have difficulties reaching efficiencies of $60 \%$ [14].

The remaining RD\&D topics for the SNG production process are in the further gas cleaning downstream the OLGA tar removal are, i.e., the removal of organic sulfur and chlorine in order to guarantee long life time of the methanation catalysts,
Table 5. Typical gas composition for different gasifiers.

\begin{tabular}{|c|c|c|c|c|}
\hline \multirow[b]{2}{*}{ Gasifier } & & CFB & CFB & Indirect \\
\hline & & $\begin{array}{l}\text { Air } \\
\text { blown }\end{array}$ & $\begin{array}{c}\mathrm{O}_{2} / \text { steam } \\
\text { blown }\end{array}$ & $\begin{array}{l}\text { Steam } \\
\text { blown }\end{array}$ \\
\hline $\mathrm{CO}$ & vol $\%_{\text {dry }}$ & 19.2 & 26.6 & 41.5 \\
\hline $\mathrm{H}_{2}$ & vol $\%_{\text {dry }}$ & 15.4 & 32.8 & 22.5 \\
\hline $\mathrm{CO} 2$ & vol $\%$ dry & 14.8 & 29.5 & 12.0 \\
\hline $\mathrm{CH}_{4}$ & vol $\%_{\text {dry }}$ & 4.2 & 7.0 & 16.2 \\
\hline $\mathrm{N}_{2}$ & vol $\%_{\text {dry }}$ & 43.8 & $0.7^{*}$ & $0.1^{*}$ \\
\hline $\mathrm{Ar}$ & vol $\%_{\text {dry }}$ & 0.5 & 0.0 & 0.0 \\
\hline $\mathrm{C}_{2+}$ & vol $\%_{\text {dry }}$ & 1.4 & 2.3 & 5.4 \\
\hline BTX & vol $\%_{\text {dry }}$ & 0.3 & 0.6 & 1.3 \\
\hline tars & $\mathrm{g} / \mathrm{m}_{\mathrm{n}}{ }^{3}$ & 9 & 12 & 32 \\
\hline
\end{tabular}

*Higher $\mathrm{N}_{2}$ values might be obtained when $\mathrm{N}_{2}$ is used for feeding.

and the catalytic conversion of remaining unsaturated hydrocarbons into components acceptable in SNG (i.e., $\mathrm{CH}_{4}$ and $\mathrm{C}_{2} \mathrm{H}_{6}$ ) [15].

\section{Coproduction of SNG and Chemicals}

A promising option to achieve even higher (economic) conversion efficiencies of biomass into products is to convert it (on a large-scale) via indirect gasification and subsequently to coproduce a variety of marketable products from biomass. After clean-up, conditioning, and $\mathrm{CO}_{2}$-removal, the indirect gasifier product gas used for SNG production can also be used to (co-)produce a variety of marketable biomass-based products [16]:

- Chemicals (methanol, BTX, olefins, phenols, naphthalene, cresylic acid, fertilizers, etc)

- Transportation fuels (FT-diesel, mixed alcohols, $\mathrm{H}_{2}$, etc)

- Gaseous energy carriers (SNG, $\mathrm{H}_{2}$ )

- Power and/or heat

Several of these products can already be obtained as intermediate coproducts during different clean-up stages, for example, in the OLGA tar removal, or downstream by applying dedicated separation technologies like selective absorption or membranes.

\section{STEP 3: DEMONSTRATING THE FLEXIBILITY OF THE OLGA TAR REMOVAL TECHNOLOGY}

\section{Alternative Gasification Concepts}

The flexibility of the OLGA tar removal technology towards the gasification concept applied upstream is demonstrated by the lab and pilot scale facilities present at ECN. On a lab scale, the OLGA was designed for removing tars downstream a BFB gasifier called the "WOB." The same unmodified lab scale OLGA, however, has also been used downstream the indirect gasifier called the "MILENA."

The typical gas compositions on a dry basis for fluidised bed (both air and oxygen/steam blown) and indirect gasifiers are presented in Table 5 [17]. 

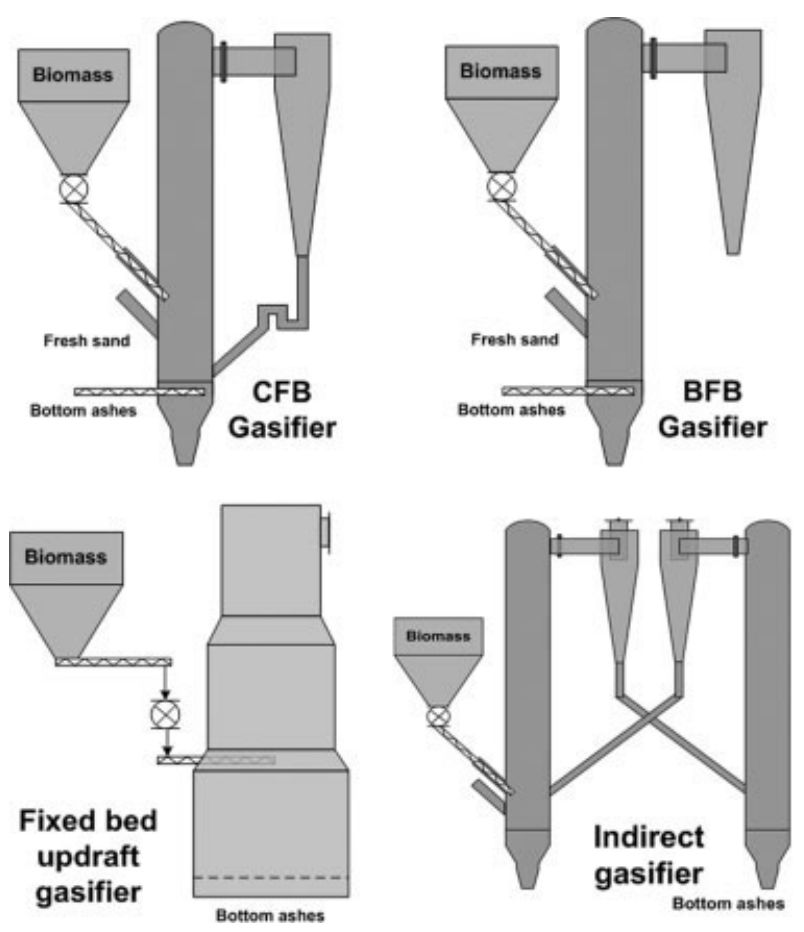

Figure 11. Proven gasification-OLGA combinations (CFB Bivkin, BFB Wob, FB PRMe, Indirect Milena).

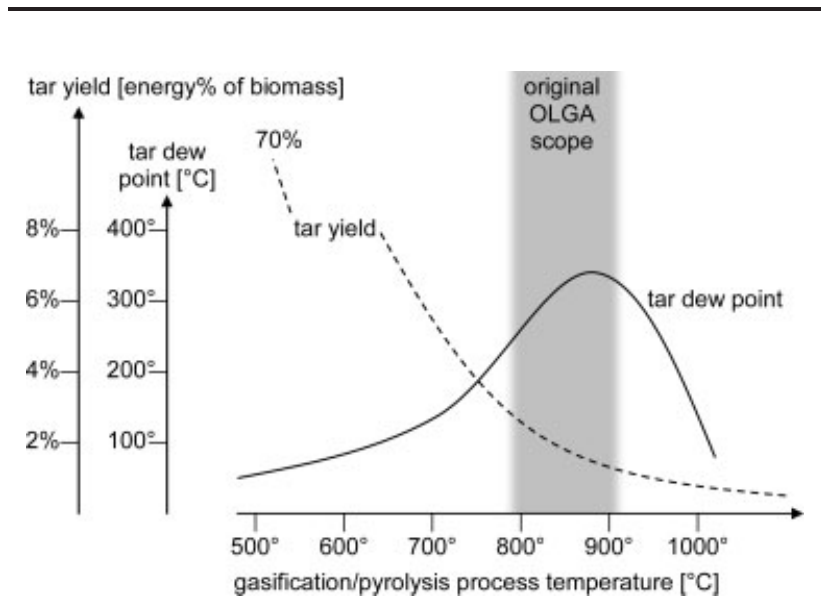

Figure 12. Effect temperature on tar dew point and yield.

Although tar levels in the product gas of an indirect gasifier can be three times as high as in an air blown gasifier, the existing OLGA lab facility is capable of removing tars from the indirect gasifier as well (as can be seen in Table 4 as well).

On a pilot scale, the OLGA facility at ECN, designed for and demonstrated downstream the air blown CFB gasifier "BIVKIN" [7, 8] has been modified only slightly in order to be taken into operation downstream the new indirect gasifier "MILENA". The main adjustments were done to the inlet of the OLGA and the tar separator (marked S-100 in Figure 3) and are related to the higher tar dew point and the amount of tars to be separated. The lengths of the columns are not adjusted.

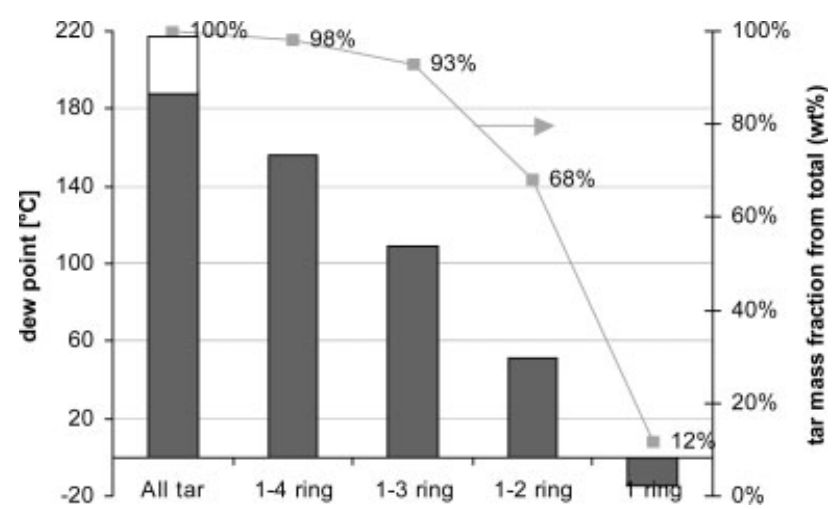

Figure 13. Effect tar composition on tar dew point.

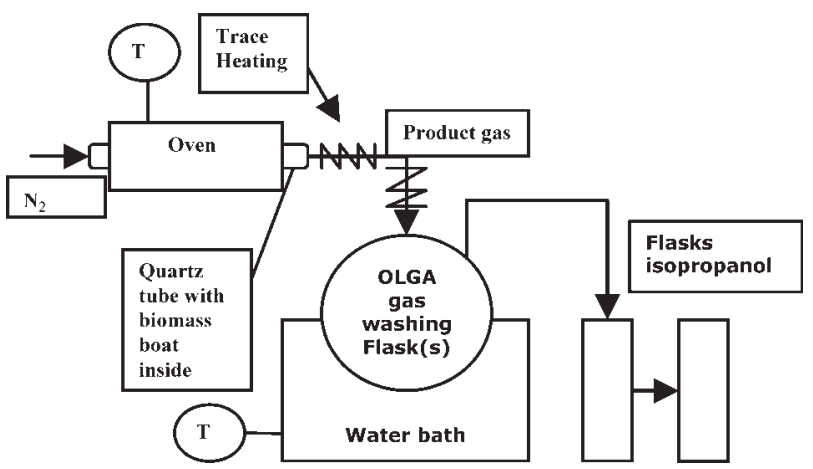

Figure 14. Micro scale pyrolysis-OLGA.

Taking into account that the OLGA tar removal technology was demonstrated downstream yet another gasification concept in Moissannes (i.e., the PRMe fixed bed gasifier), in total four combinations of different gasifiers with OLGA were successfully proven, as shown in Figure 11. Further research on OLGA applications downstream other types of gasifiers is ongoing, where in most cases however it is not the type of gasifier requiring the research but the operating conditions of the gasifier and the feedstock applied.

\section{Alternative Operating Conditions}

Although originally designed for tar removal downstream gasifiers operated at $800-900^{\circ} \mathrm{C}$, the OLGA technology in time has been tested downstream gasifiers operated at lower temperatures as well, showing that OLGA is not limited to gasifiers operated at $800-900^{\circ} \mathrm{C}$. At lower gasification temperature the tar yield will increase, however the tar dewpoint (i.e. the critical parameter) will decrease. This is illustrated indicatively by Figure 12 .

The decrease in tar dew can be explained by the fact that at lower temperatures, the tar composition shifts from large multiple ring tar components with high dew point towards smaller single or double ring tar components with lower dew points (Figure 13). Furthermore, the tar composition will shift from rather stable nonpolar components towards highly 


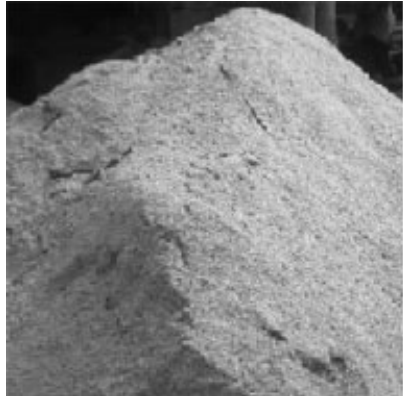

a. Wood sawdust

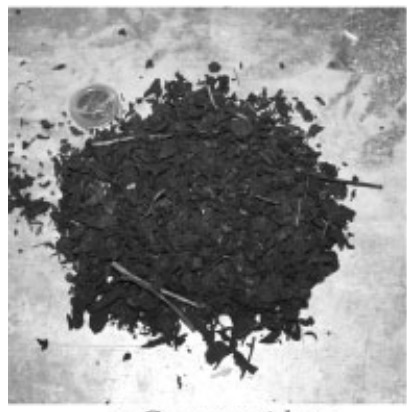

c. Grape residues

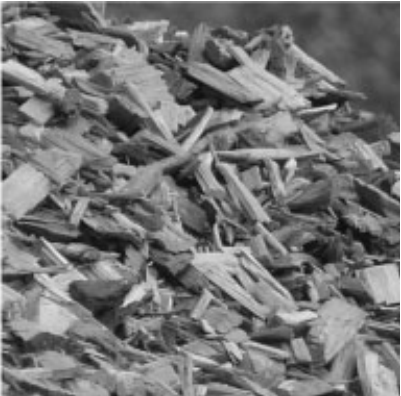

b. Wood chips

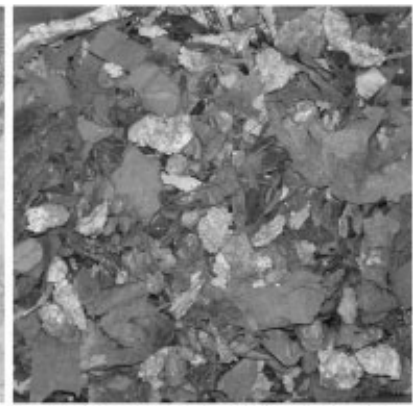

d. Refuse Derived Fuel (RDF)
Figure 15. Tested feedstocks for OLGA.

reactive polar components. As OLGA was originally designed to remove (nonpolar) tars, application of OLGA downstream gasifiers operated at lower temperatures will require some modifications.

These modifications mainly focus on changing the conventional absorption oil applied in OLGA or implementing another oil absorption step supplementary to the existing one. To study the operation of alternative oils as absorber liquids, a small (micro) scale pyrolysis was designed in connection with a very basic small scale OLGA (Figure 14).

Three different liquids were studied as alternative absorber liquids; rapeseed methyl ester, biodiesel, and glycerol. When these liquids were used as alternative absorption oil, the cleaning efficiency over the total amount of tars produced for this basic small scale OLGA was found to be 33\% for RME and $73 \%$ for glycerol.

Experiments were also performed with the liquids under investigation in combination with the conventional OLGA collector and absorber oil. The column with the liquid under investigation was placed between the collector and the presently used absorber column. The efficiency under these conditions was 44\% for RME, 58\% for biodiesel and 94\% for glycerol. Based on these results it is expected that with these oils and a well designed OLGA 99+\% efficiency will again be achieved.

\section{Alternative Feedstocks}

Although ECN successfully tested different biomass residues in its gasification facilities in the past [18] among which demolition wood (both pure and mixed with sewage sludge and paper sludge), verge grass, railroad ties, cacao shells, and different woody

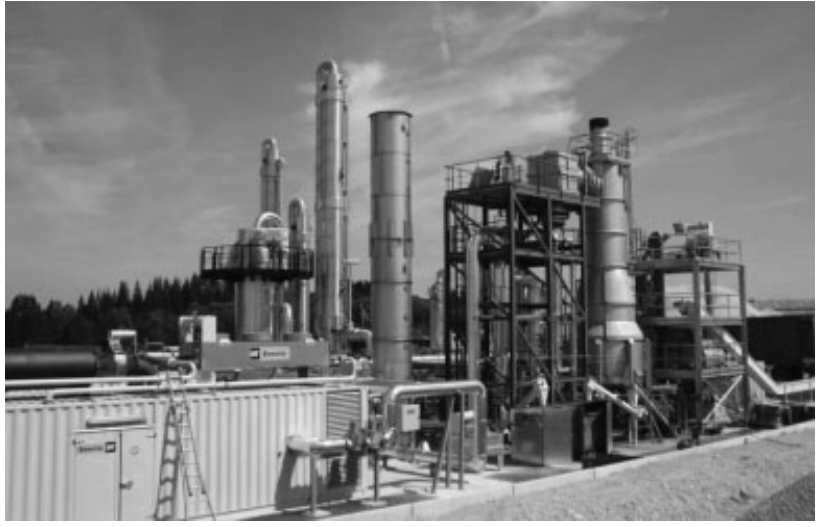

Figure 16. 1.1 $\mathrm{MW}_{\mathrm{e}}$ PRMe gasifier with OLGA in France.

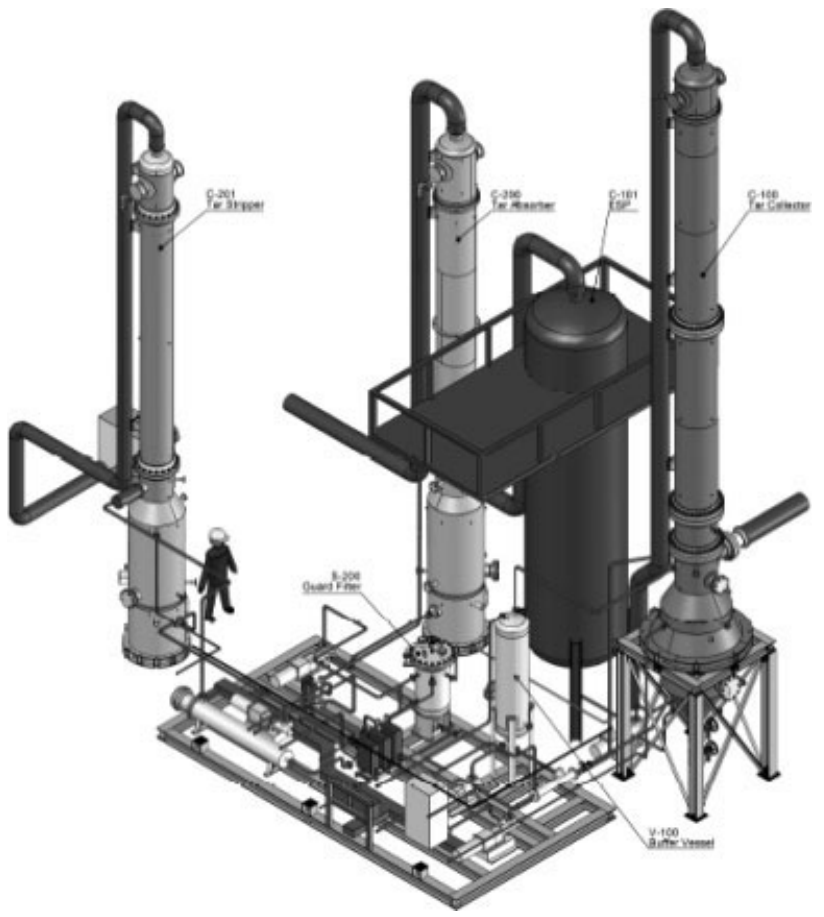

Figure 17. OLGA design for Portugal.

fuels, the development of OLGA started downstream gasifiers operated on clean wood (Figure 15a and 15b). For the lab and pilot scale testing, this meant sawdust respectively chips and pellets.

Gasification of untreated wood for the generation of electricity and heat is relatively expensive though, hence for more commercial systems, the application of cheap biomass/waste fuels is desired.

As such, the Moissannes demo plant was also operated on grape residues (Figure 15c). Recent research focused also applying the OLGA downstream gasifiers operated on more contaminated waste streams, more particularly refuse derived fuel (Figure 15d) [19].

The emphasis in this research was on a very specific industrial RDF waste stream with high plastic and chlorine content generating very specific tars. 
The first tests encountered condensation of a unusual thermoplast in the temperature area of 150$200^{\circ} \mathrm{C}$. Although the thermoplast softens and melts on heating similar to tars, its liquid viscosity is that high compared with "conventional" tars that it plugged the collector column of the OLGA.

The influence of foam polystyrene in the fuel was studied after observing extremely high styrene concentrations. However, polystyrene by itself did not lead to fouling. It then was thought [19] that the reaction towards the thermoplast could be attributed to the combined presence of (i) the polystyrene in the RDF fuel, (ii) the also highly present chlorine as a catalyst for the polymerization reactions, and (iii) at least one other tar component, likely released from another component present in the RDF fuel.

To verify this thesis, a chlorine removal step was installed upstream the OLGA. The chlorine removal based on a sodium carbonate impregnated alumina oxide carrier was hence operated above the tar dew point of the product gas.

By removing the chlorine upstream OLGA, the formation of the thermoplast could be avoided and tar removal with OLGA operated as expected and without any further problems.

\section{COMMERCIAL GASIFICATION PROJECTS INCLUDING THE OLGA TECHNOLOGY}

In France, OLGA was commercially demonstrated with a feedstock of wood and wine (grape) distillery residue [11] (Figure 16). The size for this demonstration was relatively large, $4 \mathrm{MW}_{\text {th }}$, resulting in 1.1 $\mathrm{MW}_{\mathrm{e}}$ with a gas engine, and OLGA showing excellent efficiencies, although the plant design was made before the end of the duration test in March 2006 at ECN.

New projects are currently developed world wide by the Dahlman Industrial Group, taking into account a variety of (biomass) feedstock as well as different end products (i.e. CHP, as well as SNG and transportation fuels).

In Portugal, the first commercial project will be started up beginning 2010 with a feedstock of one tonnes chicken litter per hour, to produce $1 \mathrm{MW}_{\mathrm{e}}$ in a gas engine. Figure 17 provides an illustration of the design and the footprint of that OLGA, which will be the first OLGA taking into account all the improvements made in the pilot and demo phase, in particular relating to operational aspects.

\section{CONCLUSIONS AND OUTLOOK}

The OLGA technology development started in 2001. With a successful duration test in Petten, OLGA was launched to the market by Dahlman in 2007. Valuable experience is gained in the commercial demonstration in France after which the technology was optimized by making system controls fully automatic and more operator friendly.

Optimization has not been required though in the gas cleaning qualities, OLGA always showed to be a very efficient, flexible, and reliable gas cleaning technology. This accounts not only for tar removal, but also for (dioxin) emission control.
Although OLGA can be considered as proven technology for many applications and downstream different gasifiers, for some applications (e.g., low temperature gasification or bad feedstock) some additional testing work on $\mathrm{lab}$ and pilot scale at ECN is advised and performed though to ensure successful operation on a commercial scale.

ECN continues its work on the sustainable production of fuels and chemicals [20], with OLGA having shown to be successful as well as efficient cleaning upstream catalytic processes for FT-diesel or SNG production.

\section{LITERATURE CITED}

1. Könemann, H.W.J. (2008). OLGA tar removalBiomass gasification to electricity and more. Maassluis: Dahlman Industrial Group.

2. Vreugdenhil, B.J. Thersites: Website for tar dewpoint calculations. Available at: http://www. thersites.nl. Accessed June 2009.

3. Bergman, P.C.A., Van Paasen, S.V.B., \& Boerrigter, H. (2003). The novel "OLGA" technology for complete tar removal from biomass producer gas, Energy research Centre of the Netherlands (ECN). In A.V.Bridgwater (Eds.), Proceedings of the expert meeting on pyrolysis and gasification of biomass and waste, Strasbourg, France: CPL press.

4. Boerrigter, H., \& Bergman, P.C.A. (2005). Method and system for gasifying biomass. European patent EP 1419222

5. Rabou, L.P.L.M., Zwart, R.W.R., Vreugdenhil, B.J., \& Bos, A. Tar in biomass producer gas: an enduring challenge. Energy research Centre of the Netherlands (ECN), Energy \& Fuels, submitted for publication.

6. Zwart, R.W.R. (2009). Gas cleaning-Status report 2009. Petten: Energy research Centre of the Netherlands (ECN); ECN-E-08-078.

7. Verhoeff, F., Rabou, L.P.L.M., Van Paasen, S.V.B., Emmen, R., Buwalda, R.A., \& Klein Teeselink, H. (2006). Preparation BioCHP: 1000 hours testing duration test with integral biomass gasification system (in Dutch); Petten: Energy research Centre of the Netherlands (ECN); ECN-E-06-044.

8. Verhoeff, F., Van Paasen, S.V.B., Rabou, L.P.L.M., Emmen, R., Buwalda, R.A., \& Klein Teeselink, H. (2007). 700 hours duration test with integral 500 $\mathrm{kW}_{\text {th }}$ biomass gasification system, Energy research Centre of the Netherlands (ECN), Presented at the $15^{\text {th }}$ European biomass conference, Berlin.

9. Cieplik, M.K. \& Kamp, W.L. (2009). Dioxin Formation and Abatement in Biomass Gasification, The 2009 International conference on thermochemical biomass conversion science; September 16-18, Chicago, Illinois.

10. Van Paasen, S.V.B., Ceiplik, M.K., \& Phokawat, N.P. (2006). Gasification of non- woody biomass: economic and technical perspectives of chlorine and sulphur removal from product gas. Petten: Energy research Centre of the Netherlands (ECN); ECN-E-06-032. 
11. Könemann, H.W.J. (2007). OLGA Tar Removal-4 $\mathrm{MW}_{\text {th }}$ commercial demonstration biomass gasification in France, Dahlman Industrial Group, Presented at the gasification technology conference, San Francisco.

12. Boerrigter, H., Slort, D.J., Bodenstaff, H., Den Uil, H., Rabou, L.P.L.M., Calis, H.P., \& Kaandorp, A.J. (2004) Gas cleaning for integrated biomass gasification (BG) and Fischer-Tropsch (FT) systems. Petten: Energy research Centre of the Netherlands (ECN); ECN-C-04-056.

13. Van Paasen, S.V.B. (2007). Advanced gas cleaning, Energy research Centre of the Netherlands (ECN), Presented at energy convent, Stockholm.

14. McKeough, P., \& Kurkela, E. (2008). Process evaluations and design studies in the UCG project 2004-2007. Espoo: VTT Technical Research Centre of Finland; VTT research notes 2434.

15. Zwart, R.W.R., \& Mäkinen, T. (2009). RD\&D needs and recommendations for the commercialisation of the production and use of renewable substitute natural gas from biomass. Petten: Energy research Centre of the Netherlands (ECN); ECN-BKM-2009-341.

16. Zwart, R.W.R., \& Van der Drift, A. (2007). Large scale Fischer-Tropsch diesel production-Opportunities and challenges to shift from black (coal) to green (biomass), Energy research Centre of the Netherlands (ECN). Presented at the 3rd international conference on renewable resources and biorefineries, Ghent.

17. Zwart, R.W.R. (2003). Technical, economic and environmental potential of co-firing of biomass and waste in natural gas fired turbines and combined cycles. Petten: Energy research Centre of the Netherlands (ECN); ECN-RX-03-003.

18. Van der Drift, A., Van Doorn, J., \& Vermeulen, J.W. (2001). Ten residual biomass fuels for circulating fluidized bed gasification, Energy research Centre of the Netherlands (ECN), Petten. Biomass and Bioenergy, 20, 45-56.

19. Visser, H.J.M., Zwart, R.W.R., Könemann, J.W., \& Geusebroek, M. (2008). RDF-gasification part 1: Characterizing the use of RDF as fuel and solving the tar problem by an in-depth laboratory study, Energy research Centre of the Netherlands (ECN), Presented at the 2nd international symposium on energy from biomass and waste, Venice.

20. Van der Drift, A. (2009). The ECN/HVC project for BioSNG, Energy research Centre of the Netherlands (ECN). Presented at the 2nd stakeholder plenary meeting of the European biofuels technology platform. 